\title{
Analysis of Service Mode and Innovation Trend of Logistics Supply Chain Finance*
}

\author{
Yuanqing $\mathrm{Hu}$ \\ Hunan Modern Logistics College \\ Changsha, China 410131
}

\begin{abstract}
The development of logistics supply chain finance has a positive effect on financial business innovation, which eases the financial pressure on small and medium enterprises (SMEs) and improves the profitability of logistics companies. This paper summarizes and analyzes the financial service model of logistics supply chain and its basic principles, and briefly analyzes the innovation trends of supply chain finance. The research results of this paper have certain guiding significance for financial innovation and business development of financial institutions, financing companies, and core companies in the logistics supply chain.
\end{abstract}

Keywords-logistics supply chain finance; service model; innovation trends

\section{INTRODUCTION}

Logistics supply chain finance is a financing activity in which the core enterprises of the logistics supply chain use financial tools to effectively organize and adjust the monetary funds in the logistics field to realize the valueadded logistics.

As a capital-intensive industry, the logistics supply chain service industry has a large demand for capital turnover, especially for commodity supply chain services, which needs to match a large amount of funds. At the same time, platform integration and coordination require more financial support and innovation, therefore, the ability to obtain funds, especially the ability to obtain funds at low cost, is an important factor affecting the competitiveness of supply chain companies.

\section{Prospects and SignificAnCE OF SupPly Chain FINANCIAL SERVICES}

\section{A. Broad Development Space for Supply Chain Finance}

The emergence of logistics supply chain finance can effectively support the development of a large number of upstream and downstream SMEs that are dependent on core enterprises. Therefore, supply chain finance is also considered to be a feasible path to solve the financing difficulties of SMEs. In the context of China's overcapacity supply and financial disintermediation, there is plenty of room for future development of the supply chain finance

*Fund: 2018 Hunan Provincial Social Science Achievement Review Committee Project; Project No.: XSP18YBC074. business of Lemashi.

Information flow services for supply chain management include bar code management, in-transit query, data reporting, and development of supply chain management systems. It is a data collection process for the entire process of business flow, logistics, and capital flow. The embedded characteristics of supply chain management make it possible for supply chain management companies to enrich customer service content and create greater economic value based on data analysis.

\section{B. Realizing Services from Capital Flow Management to Supply Chain Finance}

Traditional supply chain financial services mainly include banks providing financing and other settlement and wealth management services to customers (core enterprises), while providing the convenience of timely receipt of loans to suppliers of these customers, or providing prepayment on behalf of their distributors and services such as inventory financing. In the context of supply chain management service outsourcing, supply chain management service providers can rely on their control of business flow, logistics, capital flow, and information flow in front, middle, and back of the supply chain to achieve dynamic supervision and risk control of goods and funds in the supply chain operation, making supply chain management service providers become natural core companies in the supply chain, thus providing financial services to upstream and downstream enterprises. The development of supply chain financial services by Lemashi Logistics supply chain management service providers can not only open up new business models and improve profitability, but also increase customer stickiness to promote the growth of the company's supply chain business volume.

\section{DEVELOPMENT AND DESIGN OF LOGISTICS SUPPLY CHAIN FinANCIAL SER VICES}

With the continuous development of modern finance and modern logistics, there are more and more forms of logistics supply chain finance. According to the business content of finance in modern logistics, logistics finance business can be divided into:

- Logistics settlement financial model

- Logistics warehouse receipt financial model 
institutions, etc.), while helping the seller to collect cash from the buyer, and then transfer the payment to the delivery company and charge a percentage of it. The collection on delivery mode is the primary stage of logistics finance. From the perspective of profitability, the benefits it directly belongs to logistics supply chain companies, and manufacturers and consumers have obtained more convenient services.

2) Advance payment for goods service

The advance payment for goods service ("Fig. 1") refers to the "bank pledge loan business". The consignor transfers the delivery right to the bank, and the bank provides a certain percentage of financing according to market conditions. When the delivery party repays the payment to the bank, the bank issues a delivery instruction to the third-party logistics company and returns the delivery right to the delivery person.

1) Collection on delivery service

The collection on delivery service is that the logistics supply chain companies provide physical delivery for enterprises (mostly various mail order companies, ecommerce companies, business enterprises, financial

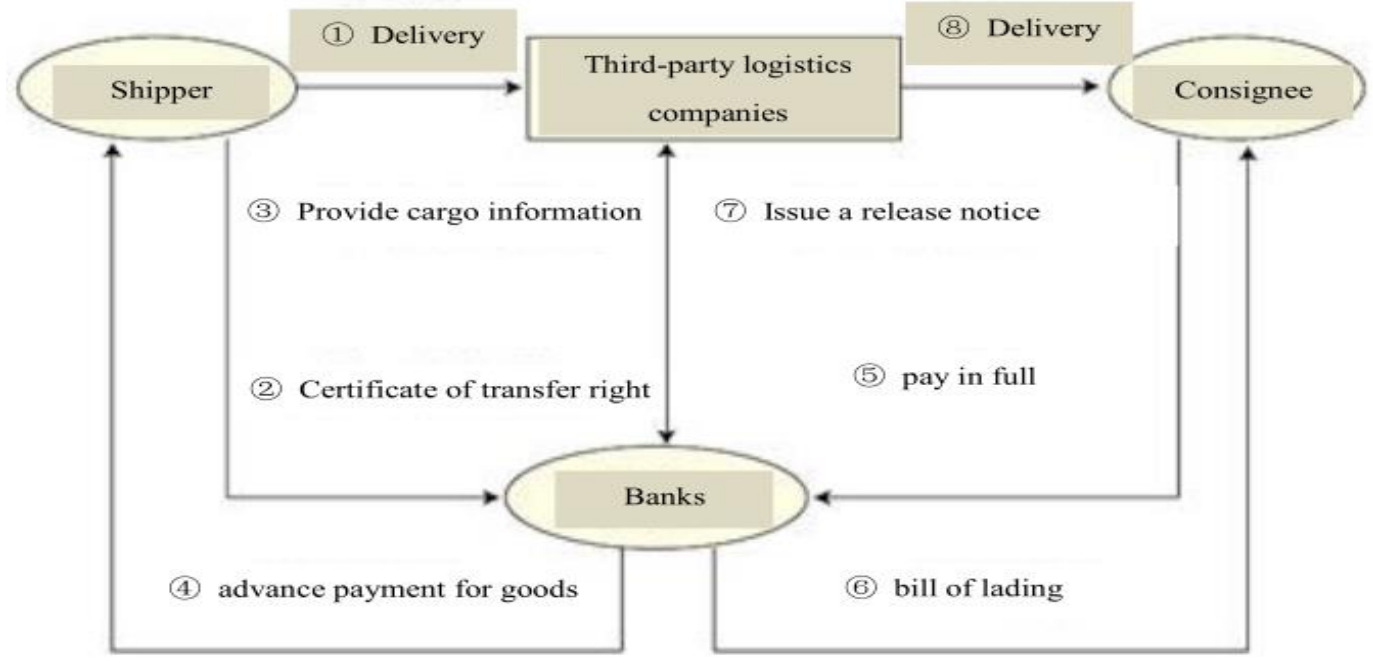

Fig. 1. Advance payment for goods model.

a) Analysis of advance payment for goods business function

Under the mode of advance payment for goods, the role of logistics enterprises has changed from the original commercial credit subject to a supporting role in providing goods information to banks, undertaking goods delivery, and helping to control risks.

From the perspective of profits, manufacturers have obtained financing, banks have received interest income, and logistics supply chain companies have also made profits because they provide services such as logistics information and logistics supervision.

In order to control risks, banks need to understand the specifications, models, quality, original price, net value, sales area, underwriters, etc. of the pledged property. They need to look carefully at the original document of the right of goods and identify the authenticity to distinguish the true from the false. These tasks are beyond the bank's daily business scope.
Therefore, banks can't do it without the assistance of thirdparty logistics companies. Generally, commodities are changing, and it is impossible for banks to understand their daily changes. Safety stock levels are the bottom line for financing. However, if third-party logistics supply chain companies can grasp the distribution of commodities and provide commodity flows to banks, this limit can be greatly increased. Under the condition that the reputation and integrity system is not yet complete, the acquisition of information such as the distribution of outlets, single-point sales, average purchase cycle, and settlement credit depends on third-party logistics companies. Only in this way can the entire process of capital turnover be transparent, so that banks and shippers know the condition of the goods at any time and better grasp the risks.

3) Acceptance bills business: acceptance bills business is also known as confirmed warehouse business

Functional analysis of acceptance bills business (confirmed warehouse business) ("Fig. 2") is as follows: 


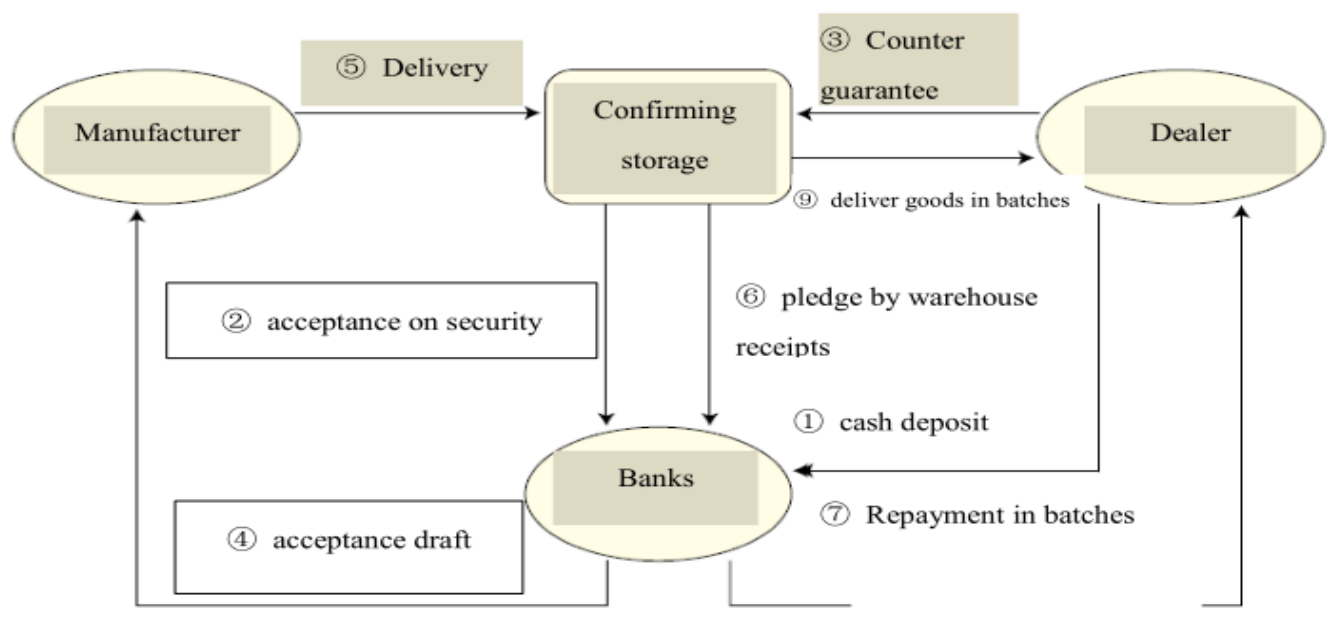

(8) Warehouse receipt separate bill of lading

Fig. 2. Confirming storage pattern diagram.

By applying to the bank for acceptance bills, the dealers actually receive indirect financing, which eases the tightness of the company's working capital. Manufacturers can get payment from the bank when the acceptance bill is due and cashed, without having to wait for the buyer to pay the bank. Through the confirmed warehouse model, the cash pressure of both parties in the transaction is relieved, and capital turnover is provided, truly achieving a multi-win situation for manufacturers, distributors, logistics companies and banks. Banks earn income by issuing acceptance bills for buyer businesses.

The core logistics company (confirmed warehouse) of the supply chain benefits from depositing for the buyer's enterprise and managing the goods, as well as providing the bank with value assessment and pledge supervision intermediary services.

\section{B. Logistics Credit Extension Financial Model}

Logistics credit extension finance refers to financial institutions granting certain credit lines to core logistics companies based on the scale, operating performance, operating status, asset-liability ratio and credit level of the logistics companies. Core logistics companies directly use these credit lines to provide flexible pledges to related companies. Core companies in the logistics supply chain directly monitor the entire process of the pledge loan business, while financial institutions basically do not participate in the specific operation of the pledge loan project.

The logistics credit extension financial model helps companies to obtain financing more conveniently and reduces the fussy links of the original pledge loan. It also helps to improve the bank's ability to monitor pledge loans to more flexibly develop pledge loan services and optimize its business processes and work steps of its pledged loans to reduce loan risks. From a profit perspective, the credit extension financial model and warehouse receipt financial model are basically similar in profit model, but since banks do not participate in the specific operation of the pledge loan project, pledge loans are issued by core companies in the logistics supply chain, and the process is simpler and the form is more flexible, which also greatly save the transaction costs between banks and supplier companies, thereby optimizing the capital cost of the supply chain operation as a whole.

\section{Logistics Warehouse Receipt Financial Model}

1) Finance-transportation and warehouse financing: it is the main form of logistics warehouse receipt finance

Its basic working principle is as follows ("Fig. 3"):

The production and operation enterprise first deposits the raw materials it purchases as collateral into the financetransportation and warehouse and obtains a loan from the cooperative bank accordingly, and then repays in stages during its subsequent production and operation process. Third-party logistics companies provide services such as the storage of pledged goods, value assessment, destination supervision, and credit guarantee, so as to build a bridge between banks and enterprises. Its essence is to transform the collaterals that banks do not want to accept into the collaterals that they are willing to accept, and then use them as credit collateral for credit financing. 
Quality supervision and

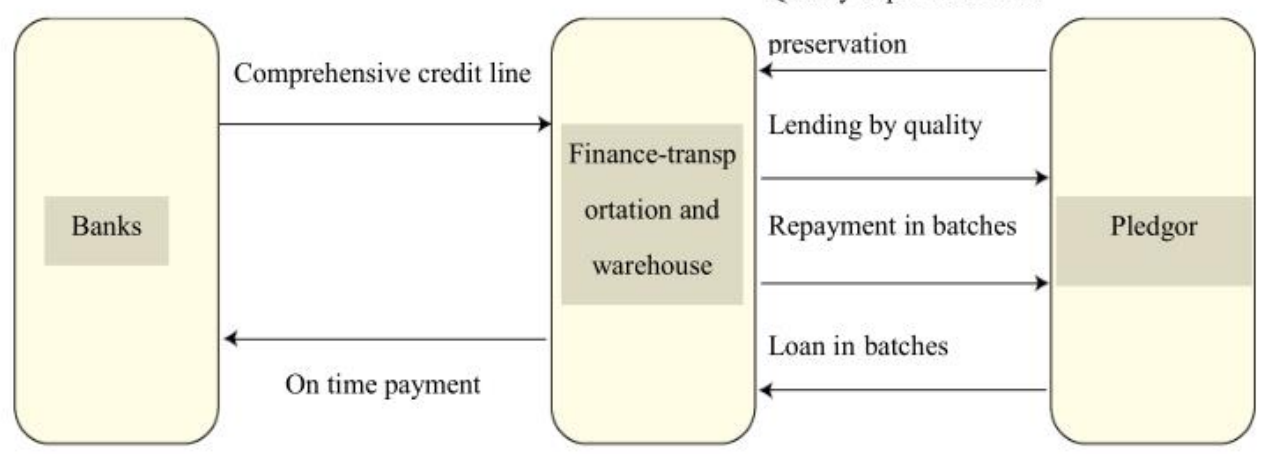

Fig. 3. Finance-transportation and warehouse model.

From the perspective of profit: supplier companies can realize financing through current assets. Banks can expand their current asset loan business, which reduces both the cost of difference between deposits and loans and increases interest income on loans. The core logistics company's revenue comes from the storage and management of goods for supplier companies and the provision of value evaluation and pledge supervision intermediary services for supplier companies and banks.

The logistics supply chain finance-transportation and warehouse center can directly use these credit lines to provide flexible pledge loan business to related companies. Finance-transportation and warehouse directly monitors the entire process of pledge loan business, while financial institutions basically do not participate in the specific operation of the pledge loan project.

Finance-transportation and warehouse directly negotiates with companies that require pledge loans, and on behalf of financial institutions, signs pledge loan contracts and warehousing management service agreements with loan companies, while providing pledge financing to enterprises, it also provides warehousing management services and supervision services for corporate pledged hostages. In this way, the two tasks of applying for loans and storing goods will be integrated to improve the operation efficiency of the pledge loan business.

2) Other logistics warehouse receipt financial models

With the development of modern logistics and finance, logistics warehouse receipt finance is also constantly innovating, and multiple logistics center warehouse receipt models and reverse guarantee models have emerged.

The multi-logistic center warehouse receipt model is an extension of the geographic location based on the warehouse receipt model. According to different customers, logistics enterprises integrate social warehouse resources or even the customer's own warehouse, and conduct pledge supervision nearby to reduce customer costs.

The reverse guaranty model expands the pledge subject. Instead of directly delivering the bank's current assets as collateral, the logistics company controls the collateral, which greatly simplifies the procedure and reduces the transaction costs of supply chain participants.

\section{INNOVATION TREND OF SUPPLY CHAIN FINANCIAL SERVICES IN THE INTERNET FINANCE ENVIRONMENT}

Logistics SaaS finance ("Fig. 4") is the new outlet of the current offline trillion markets. Supply chain management companies must seize the opportunity of innovation in supply chain financial services in the context of the Internet financial environment, make early preparations, and explore the "supply chain financial service gold mine" of tens of millions of small business enterprises.

With the advancement of industrial informatization, represented by various $\mathrm{B} 2 \mathrm{~B}$ and $\mathrm{B} 2 \mathrm{C}$ platforms, the pure credit granting business is purely based on logistics, information flow, capital flow and the self-repaying characteristics of funds in the trade process, which has significantly weakened its dependence on core companies, further expanding the scope of supply chain finance and pushing supply chain finance into the 2.0 stage.

Logistics is an indispensable basic link in business circulation and an important carrier of "information flow" and "commodity flow" in the three-in-one integration of supply chain finance. The informationization of logistics can in turn empower thousands of small and medium B merchants in the business field, and become an important breakthrough for the forward evolution of supply chain finance - logistics SaaS Fin-Tech finance, opening a new outlet for supply chain finance. 


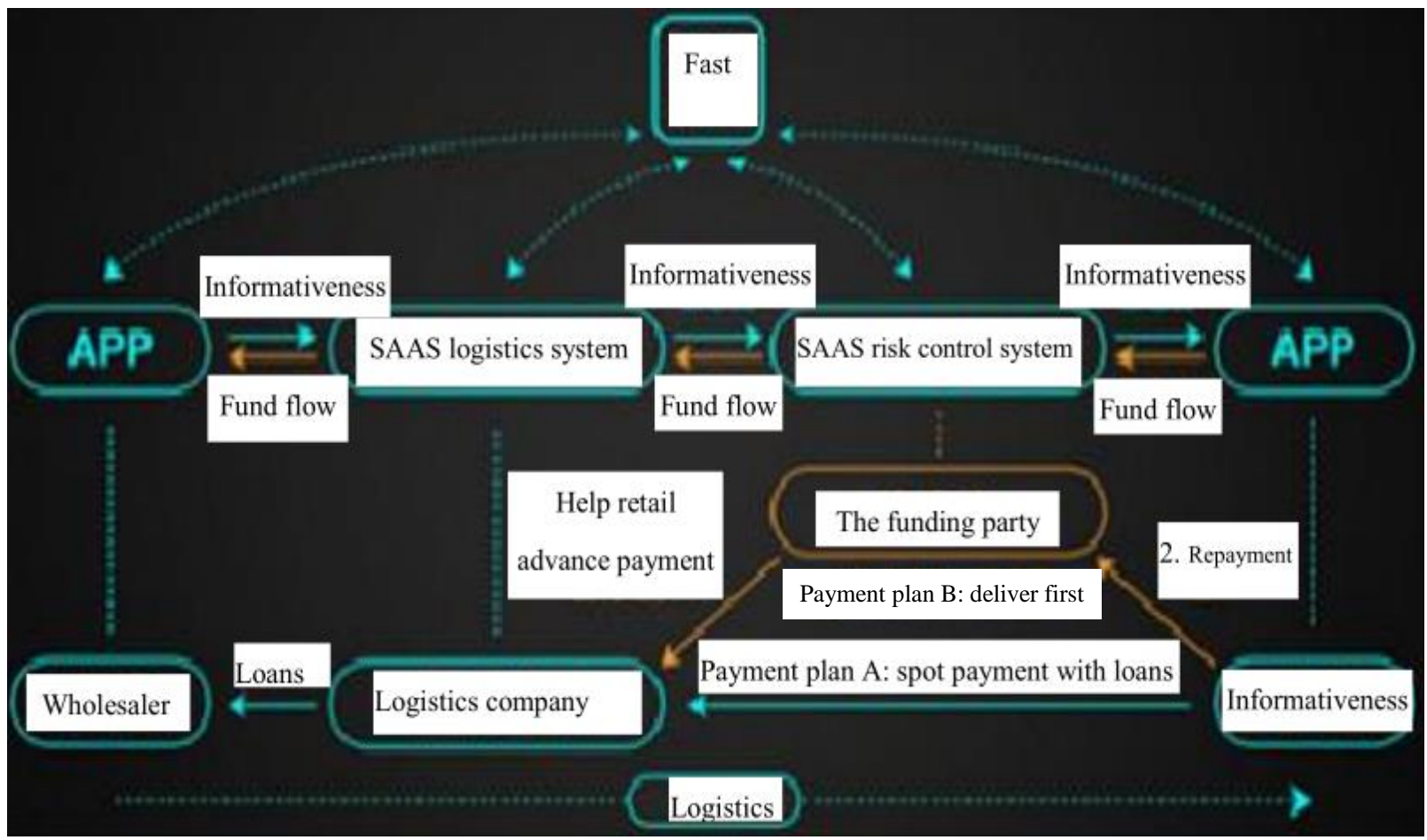

Fig. 4. SaaS-based logistics business group supply chain financial model.

The new generation of logistics technology integrated service platform, Quick Freight, has made a good attempt: since the end of 2014, the Didi platform was launched to connect the supply and demand sides of the freight. Then, it also successively launched cTMS (Transportation Management System) professional urban distribution management system, nTMS professional less-than-truckload management system and 3TMS professional three-party logistics system, completing the layout of the transportation management system output of three types of business: intracity distribution, network less-than-truckload and the thirdparty logistics. These all provide the foundation and development ideas for logistics SaaS Fin-Tech finance.

\section{CONCLUSION}

The development of modern logistics is inseparable from the support of financial services. Combining logistics services and financial services to innovate business models is one of the main ways for third-party logistics companies, financial institutions or related companies to seek advantages in market competition. Studying the coordinated development mechanism of finance and logistics, that is, the study of logistics supply chain finance, is not only a requirement to solve the plight of SMEs and achieve a winwin situation in the "supply chain", but also an effective way for financial companies to carry out business innovation and improve their competitiveness. However, the rise of this new type of business has also brought different risks to financial institutions and core companies in the logistics supply chain than in the past. Understanding and controlling these risks is the key to the success of logistics supply chain finance.

\section{REFERENCES}

[1] Song Yan, Li Weijie. Logistics Finance: Motivation, Development Model and Risk Prevention [J]. Financial Accounting, 2010 (02): 912. (in Chinese)

[2] Li Can. Analysis of the Whole Process of Logistics Financial Risk Management [J]. Modern Economic Information, 2016 (22): 263. (in Chinese)

[3] Wang Qujian, Wang Jiangbo, Yu Han. Analysis of Logistics Finance Business Model and Risk Management [J]. Logistics Engineering and Management, 2015, 37 (09): 97-98. (in Chinese) 